\title{
APROVEITAMENTO TECNOLÓGICO DAS SEMENTES DE GOIABA (PSIDIUM GUAJAVA L.) COMO FARINHA NA ELABORAÇÃO DE BISCOITOS
}

\author{
MÁRCIA LILIANE RIPPEL SILVEIRA ${ }^{1 *}$ \\ CLARISSA OBEM DOS SANTOS* \\ NEIDI GARCIA PENNA* \\ CLÁUDIA KAEHLER SAUTTER* \\ CLÁUDIA SEVERO DA ROSA** \\ SILVANA MARIA MICHELIN BERTAGNOLLI"**
}

\begin{abstract}
Este trabalho teve como objetivo investigar o potencial de utilização das sementes de goiaba como farinha na elaboração de biscoitos. A composição físico-química da farinha de sementes de goiaba (FSG) foi determinada, e posteriormente, foram elaborados biscoitos com 10 , 30 e $50 \%$ de FSG em substituição parcial à farinha de trigo. Os biscoitos foram avaliados quanto as suas características físicas, químicas e sensoriais. A FSG apresentou teor de umidade em acordo com o padrão exigido pela legislação brasileira e valores elevados de proteína, lipídios e fibra alimentar, com destaque para a fração insolúvel. A adição gradual desta farinha aos biscoitos elevou os teores de lipídios e fibra alimentar e reduziu os teores de umidade, carboidratos e valor energético. O incremento da FSG aos biscoitos influenciou os parâmetros de cor, dureza instrumental, peso e diâmetro pós-cocção. Os biscoitos elaborados apresentaram propriedades sensoriais aceitáveis, sendo os percentuais de substituição utilizados neste estudo aceitos pelos julgadores, dentre todos os atributos avaliados. Conclui-se que, a semente de goiaba é um ingrediente alternativo para o aproveitamento de um produto normalmente descartado e a farinha obtida a partir deste coproduto é uma alternativa para a substituição parcial da farinha de trigo em biscoitos visando melhorar seu valor nutritivo sem interferir nas características sensoriais.
\end{abstract}

* Programa de Pós-graduação em Ciência e Tecnologia dos Alimentos - Universidade Federal de Santa Maria - UFSM - 97105-900 - Santa Maria - RS - Brasil. E-mail: marciarippel@gmail.com; clarissa_obem@ hotmail.com

** Departamento de Tecnologia e Ciência dos Alimentos - Universidade Federal de Santa Maria - UFSM - 97105-900 - Santa Maria - RS - Brasil. E-mail: ngpenna@gmail.com; cksautter@gmail.com; claudiasr37@yahoo.com.br

*** Centro Universitário Franciscano - UNIFRA - 97010-491 - Santa Maria - RS - Brasil. E-mail: silvibert@ yahoo.com.br 


\section{INTRODUÇÃO}

O Brasil é um dos maiores produtores mundiais de goiaba, e em regiões tropicais e subtropicais a goiaba é um dos frutos de maior importância, não só devido ao seu elevado valor nutritivo, mas também pela excelente aceitação do consumo in natura favorecido pelas suas características de sabor e aroma além, da sua grande aplicação industrial (UCHOA et al., 2008; NASCIMENTO; ARAÚJO; MELO, 2010). Suas qualidades fazem com que a goiaba tenha merecido atenção especial, tanto para o consumo como para o desenvolvimento de novos produtos.

A maior parte da produção brasileira de goiabas é destinada à indústria para a elaboração de diversos produtos, como doces, sucos, geleias, polpa congelada, entre outros. Porém, durante as etapas do processo de beneficiamento dos frutos são recolhidos materiais não aproveitados na produção industrial, os chamados coprodutos. A quase totalidade desses coprodutos é constituída pelas cascas e sementes da fruta e representam um problema tecnológico de grandes proporções para a indústria de alimentos, uma vez que precisam ser descartados (AQUINO et al., 2010; NASCIMENTO; ARAÚJO; MELO, 2010).

O desenvolvimento de alternativas para o aproveitamento dos coprodutos surgiu da necessidade de minimizar as perdas de matéria-prima, os impactos ambientais e os custos de produção. O processamento de alimentos a partir de coprodutos tem representado um seguimento importante para as indústrias, devido principalmente, ao forte apelo nutricional existente nos dias atuais para a melhoria da qualidade da dieta (FASOLIN et al., 2007; SANTANA; SILVA, 2008). Embora sejam constituídos basicamente de matéria orgânica, elevados teores de açúcares e fibra, os coprodutos de frutas não fazem parte dos hábitos alimentares da maioria das populações, porém podem ser importante fonte de nutrientes (SANTANA; SILVA, 2008; AQUINO et al., 2010).

As farinhas de coprodutos (como casca, sementes, bagaço) podem ser utilizadas como alternativa para substituição parcial da farinha de trigo na elaboração de produtos de panificação (biscoitos e pães) e massas alimentícias. As farinhas mistas são utilizadas principalmente na elaboração de biscoitos, já que esse produto possui poder atrativo e é aceito e consumido por pessoas de qualquer idade. Além disso, sua longa vida de prateleira permite que sejam produzidos em grandes quantidades e largamente distribuídos (SANTOS et al., 2011; PIOVESANA; BUENO; KLAJN, 2013).

O presente trabalho teve por objetivo foi investigar o potencial de utilização das sementes de goiaba como farinha na elaboração de biscoitos, gerando informações para a aplicabilidade direcionada deste material.

\section{MATERIAL E MÉTODOS}

A pesquisa constituiu-se de um estudo experimental, o qual foi desenvolvido nos Laboratórios do Departamento de Tecnologia e Ciência dos Alimentos da UFSM e no Núcleo Integrado de Desenvolvimento em Análises Laboratoriais (Nidal-UFSM), Santa Maria - RS.

\subsection{MATERIAL}

Para a realização deste trabalho foram utilizadas sementes de goiaba do genótipo de polpa vermelha (Psidium guajava L. var. Paluma). As sementes foram separadas da polpa manualmente com o auxílio de peneira doméstica, posteriormente foram submetidas a lavagens com água corrente sobre peneira para remoção completa dos restos de polpa. 


\subsection{MÉTODOS}

\subsubsection{Obtenção da farinha de sementes de goiaba}

As sementes de goiaba após serem secas em estufa com circulação de ar a $55{ }^{\circ} \mathrm{C}$ por 2 horas foram moídas em micromoinho (marca Marconi ${ }^{\circledR}$ ), a padronização da granulometria do material triturado foi realizada em peneira com malha de 20 mesh (marca a bronzinox). Este procedimento resultou em duas frações, a fração retida na peneira e a fração peneirada, a parte não peneirada foi descartada e a parte peneirada foi denominada de farinha de sementes de goiaba (FSG).

A determinação do rendimento da FSG foi feita gravimetricamente, através da relação entre o peso das sementes íntegras e a quantidade das diferentes frações obtidas, expresso em termos percentuais. A FSG foi então, acondicionada em sacos de polietileno, mantidos sob congelamento até a execução das análises e elaboração dos biscoitos.

\subsubsection{Caracterização físico-química da FSG}

As análises de $\mathrm{pH}$, em potenciômetro digital de bancada (Digimed ${ }^{\circledR}$, modelo DM 22) e acidez total titulável, expressa em g de ácido cítrico $100 \mathrm{~g}^{-1}$ foram realizadas conforme os métodos descritos pelo Instituto Adolfo Lutz (IAL, 2008). A atividade de água foi mensurada diretamente em equipamento específico, marca AquaLab (Decagon Devices Inc. EUA), modelo 4TEV, conforme as especificações do fabricante.

As análises da composição química da FSG foram realizadas de acordo com as técnicas descritas pela Association Of Official Analytical Chemists (AOAC, 2005), em triplicata. O teor de umidade foi determinado pelo método de secagem em estufa a $105^{\circ} \mathrm{C}$, até peso constante e a matéria mineral foi obtida por incineração do material em mufla a $550^{\circ} \mathrm{C}$ por $5 \mathrm{~h}$. O nitrogênio total foi determinado pelo método de Kjeldahl e convertido em proteína bruta pelo fator $6,25(\mathrm{~N} X 6,25)$ e os lipídios foram determinados conforme o método de Bligh e Dyer (1959). Da amostra seca foi realizada a análise dos teores de fibra alimentar total e insolúvel de acordo com o método enzímicogravimétrico 991.43 (AOAC, 2005) corrigido para proteína e cinzas. As enzimas utilizadas no método foram a $\alpha$-amilase $\left(\right.$ Termamy $^{\circledR} 2 \mathrm{X}$ ), protease (Alcalase ${ }^{\circledR} 2.4 \mathrm{~L} F \mathrm{FG}$ ) e amiloglicosidase (AMG ${ }^{\circledR} 300 \mathrm{~L}$ ), ambas obtidas da Novozymes Latin American Ltda. O conteúdo de fibra solúvel foi estimado pela diferença entre a fibra total e a fibra insolúvel. $O$ teor de carboidratos foi determinado por diferença entre a massa inicial da amostra ( $100 \mathrm{~g}$ ) e a soma das porcentagens dos teores de cinzas, proteínas, lipídios e fibra total.

\subsubsection{Formulação dos biscoitos}

As formulações dos biscoitos foram desenvolvidas mediante modificações do método padrão 10-50D (AACC,1995), com substituição parcial da farinha de trigo por FSG, nas concentrações de 10,30 e $50 \%$, em relação ao peso total da farinha de trigo da formulação original. Os demais ingredientes permaneceram constantes. Os biscoitos elaborados foram designados de tratamento (T) 1, 2 e 3. Na Tabela 1 estão descritos os ingredientes e as quantidades utilizadas nas formulações desenvolvidas.

Inicialmente, realizaram-se testes preliminares para determinar as quantidades de FSG a serem adicionadas às formulações. Os testes sensoriais informais permitiram constatar que formulações com adição superior a 50\% de FSG conduziriam a produtos com características sensoriais pouco aceitáveis, em relação as obtidas com adição inferior a $50 \%$, por razão da sua característica de textura oral "granulosa" devido à quantidade de FSG e por influenciar negativamente nas características viscoelásticas da massa. Portanto ficou evidenciada a necessidade de se elaborar formulações com teores de FSG igual ou inferior a $50 \%$.

Os ingredientes, além da farinha mista, utilizados na elaboração dos biscoitos foram adquiridos no comércio local do município de Santa Maria - RS. 


\section{TABELA 1 - INGREDIENTES E QUANTIDADES UTILIZADAS NAS FORMULAÇÕES DOS BISCOITOS DESENVOLVIDOS COM DIFERENTES CONCENTRAÇÕES DE FSG.}

\begin{tabular}{lccc}
\hline \multirow{2}{*}{ Ingredientes } & \multicolumn{3}{c}{ Tratamentos } \\
\cline { 2 - 4 } & T1 (10\%) & T2 (30\%) & T3 (50\%) \\
\hline Farinha de trigo (g) & 200,88 & 156,24 & 111,60 \\
FSG (g) & 22,32 & 66,96 & 111,60 \\
Açúcar refinado (g) & 100,00 & 100,00 & 100,00 \\
Margarina* $(\mathrm{g})$ & 67,50 & 67,50 & 67,50 \\
Fermento químico (g) & 5,00 & 5,00 & 5,00 \\
Leite em pó $(\mathrm{g})$ & 10,00 & 10,00 & 10,00 \\
Sal refinado $(\mathrm{g})$ & 2,10 & 2,10 & 2,10 \\
Ovo fresco** $(\mathrm{g})$ & 45,87 & 45,87 & 45,87 \\
Água (mL) & 30,00 & 15,00 & 10,00 \\
\hline
\end{tabular}

*Teor lipídico igual a $80 \%$ e isenta de sal.

** Valor médio.

\subsubsection{Processamento dos biscoitos}

Para o preparo dos biscoitos, inicialmente todos os ingredientes foram pesados e as farinhas de trigo e sementes de goiaba homogeneizadas nas quantidades descritas na Tabela 1.

Para elaboração da massa, primeiramente foram misturados os ovos, o açúcar, a margarina, o sal e o leite em pó, em batedeira Britânia, modelo turbo 360, até se obter um creme homogêneo. A seguir, adicionou-se, aos poucos, a mistura de farinhas composta pelas diferentes concentrações definidas nos tratamentos e o fermento químico, seguida da adição de água. Após a adição de toda a mistura de farinhas, a massa foi novamente misturada em batedeira até homogeneização completa e formação de uma massa lisa, brilhante e não quebradiça.

A massa preparada foi dividida em pequenas porções, modelada manualmente em formato circular e depositada diretamente em formas de alumínio retangular forradas com papel manteiga. Os biscoitos foram então assados em forno elétrico Fischer, modelo Gourmet Grill, à temperatura de $180{ }^{\circ} \mathrm{C}$ por aproximadamente 18 minutos, sendo antes efetuadas as análises físicas (peso, diâmetro, espessura e fator de expansão) dos biscoitos. Após assados, os biscoitos foram resfriados naturalmente à temperatura ambiente e novamente foram avaliadas as características físicas, em seguida, foram acondicionados em sacos de polietileno, devidamente identificados e as embalagens seladas até o momento das análises.

\subsection{CARACTERIZAÇÃO DOS BISCOITOS COM FSG}

\subsubsection{Composição química}

Para determinar a composição química, as análises de umidade, cinzas, proteínas e lipídios foram efetuadas conforme descrito anteriormente na caracterização da FSG. A quantidade de fibra alimentar total foi determinada, não sendo separadas as frações solúvel e insolúvel. Desta forma, o teor de fibra alimentar foi estimado a partir do conteúdo de fibra alimentar total verificado na FSG e a quantidade de fibra alimentar presente na farinha de trigo $\left(2,3 \mathrm{~g}_{100 \mathrm{~g}^{-1}}\right)$, dado obtido da Tabela Brasileira de Composição de Alimentos (TACO, 2011). Os carboidratos foram calculados por diferença, subtraindo-se de 100 os valores obtidos para umidade, proteína, lipídios, cinzas e 
fibra alimentar total. $\mathrm{O}$ valor energético total $\left(\mathrm{Kcal} \mathrm{g}^{-1}\right)$ dos produtos formulados foram calculados aplicando-se os valores de conversão de $4 \mathrm{kcal} \mathrm{g}^{-1}$ para $1 \mathrm{~g}$ de proteína e carboidrato e $9 \mathrm{kcal} \mathrm{g}^{-1}$ para $1 \mathrm{~g}$ de lipídio (BRASIL, 2003).

\subsubsection{Avaliação física}

As análises físicas foram efetuadas de acordo com os procedimentos descritos no método 10-50D (AACC, 1995), para avaliação do peso, espessura e diâmetro dos biscoitos antes e após o forneamento, e fator de expansão, calculado pela razão entre os valores de diâmetro e espessura dos biscoitos após o forneamento. As análises foram conduzidas em amostras aleatórias constituídas de seis biscoitos para cada tratamento, provenientes de uma mesma fornada, após terem atingido temperatura ambiente.

\subsubsection{Cor}

A cor dos biscoitos foi avaliada objetivamente pela reflectância no espaço de cor CIELab utilizando colorímetro (Konica Minolta ${ }^{\circledR}$, modelo CR-300). Os parâmetros de cor indicam a luminosidade $\left(L^{*}\right)$, as coordenadas de cor $\left(a^{*}\right.$ e $\left.b^{*}\right)$ da amostra, o índice de saturação $\left(C^{*}\right)$ e o ângulo de tonalidade $\left(\mathrm{h}^{\circ}\right)$. Os biscoitos utilizados para as leituras foram escolhidos aleatoriamente, e as amostras previamente trituradas foram dispostas em placas de Petri sob um fundo branco padrão. Para cada tratamento foram efetuadas seis leituras sequenciais em diferentes pontos, com homogeneização manual da amostra entre as leituras.

\subsubsection{Textura}

Os parâmetros de dureza e fraturabilidade dos biscoitos foram avaliados em texturômetro TA-XT.plus Texture Analyzer (Stable Microsystems, Surrey, England) e o equipamento foi operado pelo software Texture Expert Exponent. O texturômetro foi ajustado, segundo técnica descrita pelo próprio fabricante para textura de biscoito e por adaptação das condições propostas por Assis et al., (2009). Os biscoitos foram selecionados de forma aleatória e as determinações realizadas colocando-se os biscoitos horizontalmente em plataforma, utilizando-se lâmina de aço retangular de ponta arredondada (Upperblade) com dimensões de $9 \times 3 \mathrm{~cm}$ para cortar o biscoito ao meio. As condições do teste foram: probe 3-Point Bending Rig (HDP/3PB); medida de força em compressão; velocidade pré-teste, $2 \mathrm{~mm} . \mathrm{s}^{-1}$, velocidade de teste, $2 \mathrm{~mm} . \mathrm{s}^{-1}$; velocidade pós-teste, $10 \mathrm{~mm} . \mathrm{s}^{-1}$; distância percorrida pelo sensor, $10 \mathrm{~mm}$ e distância da abertura dos apoios da base para colocar a amostra de $20 \mathrm{~mm}$ e força de contato de $50 \mathrm{~g}$. A fraturabilidade correspondeu à altura do primeiro pico significativo, no primeiro ciclo de compressão, e a dureza ao pico máximo, também no primeiro ciclo de compressão (BOURNE, 1978). As avaliações foram efetuadas após 24 horas do assamento e os resultados representam a média aritmética de 10 repetições por tratamento.

\subsubsection{Análise sensorial}

Os biscoitos elaborados foram avaliados sensorialmente por meio de testes afetivos de ordenação quanto à preferência e aceitabilidade. Uma unidade amostral de cada formulação avaliada foi servida em forma de papel branca, devidamente identificada com números de três dígitos aleatórios.

Os testes sensoriais foram realizados em duas sessões, na primeira foi aplicado o teste de ordenação para avaliar a preferência global dos provadores em relação às formulações (IAL, 2008) considerando os atributos sensoriais de cor, aroma, sabor e textura. Esse teste foi realizado com um grupo de 70 indivíduos adultos, não treinados, foi solicitado aos provadores que ordenassem as amostras em ordem decrescente de acordo com a sua preferência (FERREIRA et al., 2000). O teste afetivo de aceitação foi realizado em uma segunda sessão com 61 provadores, utilizando-se escala hedônica estruturada verbal de sete pontos $(1=$ desgostei muitíssimo, $4=$ indiferente e $7=$ 
gostei muitíssimo) para avaliação dos atributos cor, aroma, sabor, textura e aceitação global. Nesta mesma sessão também foi aplicado o teste de intenção de compra utilizando-se escala hedônica estruturada verbal de cinco pontos ( 5 = certamente eu compraria, $3=$ talvez eu compraria/talvez eu não compraria e 1 = certamente eu não compraria) (FERREIRA et al., 2000). Os resultados foram expressos em porcentagem, de acordo com a frequência das respostas (IAL, 2008).

Para o cálculo do Índice de Aceitabilidade (IA) do produto foi adotada a expressão:

$I A(\%)=A \times 100 / B$, onde $A$ representa a nota média obtida para o produto, e $B$ a nota máxima dada ao produto. O IA com boa repercussão têm sido considerado $\geq 70 \%$ (FERREIRA et al., 2000).

\subsubsection{Aspectos éticos}

O presente estudo foi avaliado e aprovado pelo Comitê de Ética em Pesquisa da Universidade Federal de Santa Maria - UFSM, registro CAAE 18074913.8.0000.5346, em seus aspectos éticos e metodológicos atendendo as Diretrizes estabelecidas na Resolução 466/2012 (BRASIL, 2012).

\subsubsection{Análise estatística}

Os resultados obtidos nas análises realizadas foram expressos na forma de média \pm desvio padrão e submetidos à análise de variância (ANOVA). A análise comparativa dos resultados foi realizada por meio do teste de Tukey ao nível de significância de $5 \%$, utilizando o programa estatístico Statistica versão 9.0 (StatSoft Inc., Tulsa, EUA).

\section{RESULTADOS E DISCUSSÃO}

\subsection{RENDIMENTO E CARACTERIZAÇÃO FÍSICO-QUÍMICA DA FSG}

Estudos sobre a transformação dos coprodutos de frutas em farinhas têm sido desenvolvidos no intuito de avaliar o potencial nutricional e a aplicabilidade dessas farinhas como ingrediente alimentar. Para verificar o rendimento das sementes em FSG foram utilizados $800 \mathrm{~g}$ de sementes, a partir dos quais foram obtidos $592,5 \mathrm{~g}$ de FSG, o que corresponde a um rendimento de $74,06 \%$. No processo de moagem e granulometria houve uma perda de apenas $1,88 \%$, sendo essa atribuída ao manuseio e ao aspecto físico da semente, a qual se apresentou dura e de difícil moagem.

Os resultados das análises da caracterização físico-química da FSG estão apresentados na Tabela 2.

A baixa atividade de água ( $\mathrm{Aa}$ ) encontrada na FSG reduz o crescimento microbiano e impede reações bioquímicas que dependem da atividade de água. Consequentemente contribui para a conservação do produto prolongando a sua possibilidade de uso.

A acidez é um importante parâmetro na avaliação do estado de conservação de um produto alimentício. Os valores médios de $\mathrm{pH}$ e acidez encontrados para a FSG foram de 5,98 e 0,33 g de ácido cítrico $100 \mathrm{~g}^{-1}$, respectivamente. Uchoa et al., (2008) e Abud e Narain (2009) encontraram valores de acidez de 1,21 e 0,08 g de ácido cítrico $100 \mathrm{~g}^{-1}$ para o pó alimentício obtido do bagaço de goiaba e para o resíduo desidratado de goiaba, respectivamente. Em relação ao pH, esses autores verificaram valores de 4,60; 4,88 e 5,85 respectivamente. Na caracterização da farinha de resíduos de acerola, Aquino et al., (2010) encontraram para o pH o valor médio de 3,32 e segundo os autores o valor de $\mathrm{pH}$ que delimita o desenvolvimento de micro-organismos é abaixo de 4,5. $\mathrm{Na}$ FSG, o pH verificado foi superior ao valor recomendado por Aquino et al., (2010), porém está abaixo da neutralidade, que aliado ao valor reduzido de umidade e Aa favorece a estabilidade do produto, dificultando assim, o desenvolvimento de micro-organismos. 
TABELA 2 - CARACTERIZAÇÃO FÍSICO-QUÍMICA DA FSG.

\begin{tabular}{lc}
\hline \multicolumn{1}{c}{ Parâmetros } & Valores $^{*}$ \\
\hline Atividade de água & $0,11 \pm 0,01$ \\
$\mathrm{pH}$ & $5,98 \pm 0,09$ \\
$\mathrm{ATT}{ }^{* *}\left(\mathrm{~g}\right.$ de ácido cítrico $\left.100 \mathrm{~g}^{-1}\right)$ & $0,33 \pm 0,01$ \\
Umidade $\left(\mathrm{g} 100 \mathrm{~g}^{-1}\right)$ & $5,74 \pm 0,16$ \\
Proteína bruta $\left(\mathrm{g} 100 \mathrm{~g}^{-1}\right)$ & $12,77 \pm 0,43$ \\
Lipídios $\left(\mathrm{g} 100 \mathrm{~g}^{-1}\right)$ & $12,94 \pm 0,35$ \\
Matéria mineral $\left(\left(\mathrm{g} 100 \mathrm{~g}^{-1}\right)\right.$ & $1,04 \pm 0,08$ \\
Fibra alimentar $\left(\mathrm{g} 100 \mathrm{~g}^{-1}\right)$ & $51,08 \pm 0,09$ \\
$\quad$ Fibra insolúvel $\left({\left.\mathrm{g} 100 \mathrm{~g}^{-1}\right)}^{\text {Fibra solúvel }\left(\mathrm{g} 100 \mathrm{~g}^{-1}\right)}\right.$ & $47,02 \pm 0,08$ \\
Carboidratos & \\
\hline
\end{tabular}

*Valores médios \pm desvio padrão de determinações em triplicata. As médias, exceto umidade, foram calculadas em base seca. **ATT: Acidez total titulável. ${ }^{* *}$ Calculados por diferença.

Observa-se, na Tabela 2, que o teor de umidade verificado na FSG foi inferior a $15 \mathrm{~g} 100$ $\mathrm{g}^{-1}$, limite máximo de umidade preconizado para farinhas pela legislação brasileira (BRASIL, 2005). Este resultado demonstra que o processo de secagem aplicado para a obtenção desta farinha foi eficiente, pois além de reduzir o peso do material contribui para a conservação do produto tornando-o mais estável, protegendo-o da degradação enzimática e oxidativa.

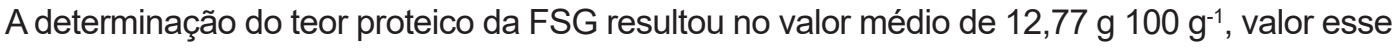
superior ao apresentado por Uchoa et al., (2008) e Abud e Narain (2009) para a farinha dos resíduos de goiaba (1,16 e 0,58 g $100 \mathrm{~g}^{-1}$, respectivamente) e por Matias et al., (2005) para o bagaço de goiaba

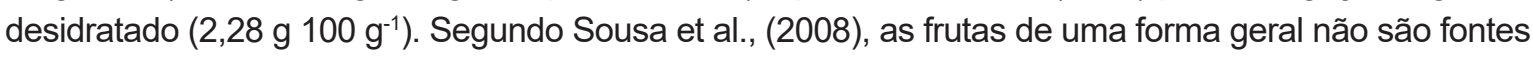
potenciais de proteínas, entretanto, parece que esse macronutriente se encontra predominantemente nas cascas e na semente. Devido a essa característica, a FSG pode se tornar de grande interesse nutricional. Autilização de produtos proteicos pela indústria alimentícia tem mostrado aumento significativo em virtude de suas características funcionais. Neste sentido, as proteínas possuem capacidade para desempenhar certas funções em determinado sistema alimentar, tais como, absorção de água, formação e estabilidade de emulsão, formação de gel e espuma, dentre outras (FONTANARI et al., 2007).

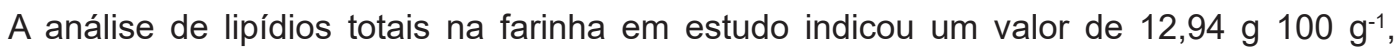
sendo este considerado elevado se comparado aos teores obtidos pelas farinhas dos resíduos do

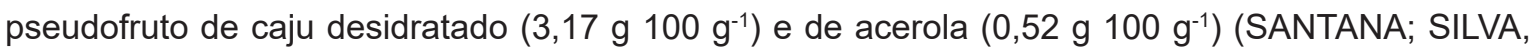
2008; AQUINO et al., 2010), Porém, teores mais elevados de lipídios foram observados por Abud e

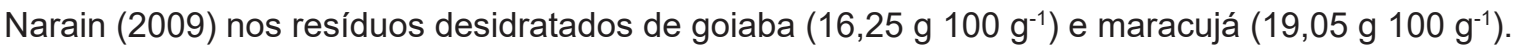

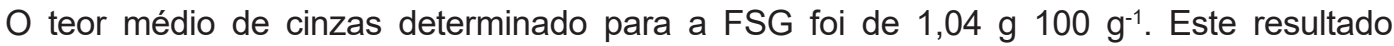
demonstra que a FSG não é uma fonte importante de matéria mineral quando comparada com outras farinhas. No trabalho de Uchoa et al., (2008) sobre o aproveitamento dos resíduos de frutas oriundos do processamento de polpa, os valores encontrados na análise de cinzas para os pós alimentícios dos resíduos de caju, goiaba e maracujá foram de 1,78; 2,14 e 2,52 g $100 \mathrm{~g}^{-1}$,respectivamente. Abud e Narain (2009) também encontraram teores elevados de matéria mineral para as farinhas dos resíduos

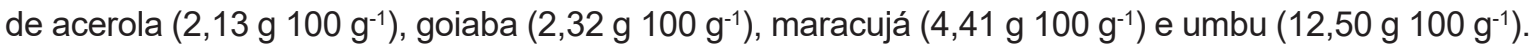


Nos estudos acima citados, além das sementes, cascas e polpas em proporções não estabelecidas também constituíam os resíduos utilizados. Esse fato pode explicar as diferenças encontradas entre o teor de matéria mineral obtido para a FSG neste trabalho e os teores reportados na literatura.

Conforme observado na Tabela 2, a FSG apresentou elevado teor de fibra alimentar total, principalmente o tipo insolúvel. O teor de fibra verificado na FSG é significativamente maior que os teores relatados por Uchoa et al., (2008), Souza; Ferreira e Vieira (2008) e Boekel et al., (2011) para o pó alimentício do resíduo de goiaba e para as farinhas dos subprodutos (flavedo, albedo e polpa) da laranja-pera e da casca do maracujá $\left(24,46 ; 21,45\right.$ e 70,67 g $100 \mathrm{~g}^{-1}$ de fibra alimentar, respectivamente). Assim como na FSG, a fração insolúvel da fibra também foi observada em maior

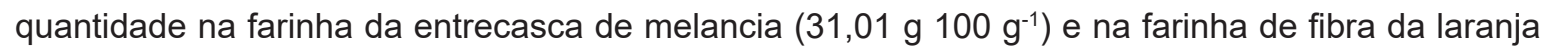

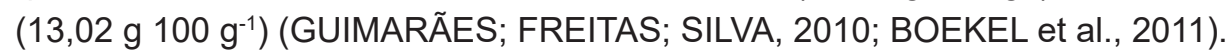

Farinhas ricas em fibra estão sendo utilizadas na elaboração de produtos de panificação e massas alimentícias, ampliando a oferta de produtos com elevado teor de fibra, tanto para os consumidores sadios quanto para aqueles que apresentam algumas doenças crônicas não transmissíveis (GUIMARÃES; FREITAS; SILVA, 2010). Como observado, a FSG apresentou um alto teor de fibra alimentar, tal fato sugere que, a incorporação desta farinha em produtos alimentícios, como biscoitos, pães e massas alimentícias amplamente consumidos pela população, pode ser considerada uma alternativa para o incremento de fibra alimentar na dieta.

A FSG apresentou 22,17 g $100 \mathrm{~g}^{-1}$ de carboidratos, este valor está próximo dos resultados

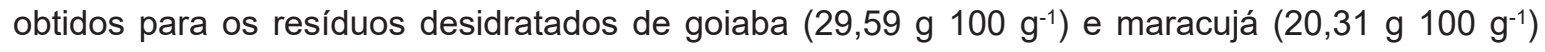
(ABUD; NARAIN, 2009). Concentrações mais elevadas de carboidratos foram encontradas para as

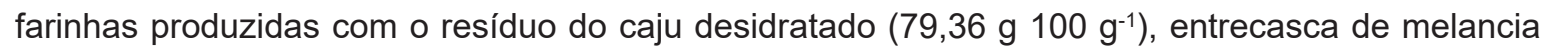

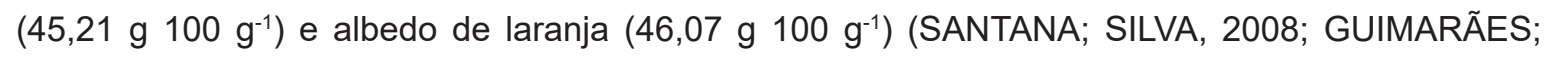
FREITAS; SILVA, 2010; SANTOS et al., 2011).

\subsection{CARACTERIZAÇÃO DOS BISCOITOS COM FSG}

\subsubsection{Composição química}

$\mathrm{Na}$ Tabela 3 são apresentados os resultados da avaliação da composição química dos biscoitos dos tratamentos 1, 2 e 3 elaborados com substituição parcial da farinha de trigo por FSG.

\section{TABELA 3 - COMPOSIÇÃO QUÍMICA DOS BISCOITOS ELABORADOS COM DIFERENTES CONCENTRAÇÕES DE FSG.}

\begin{tabular}{|c|c|c|c|}
\hline \multirow{2}{*}{$\begin{array}{l}\text { Constituintes } \\
\left(\mathrm{g}^{1} 100 \mathrm{~g}^{-1}\right)\end{array}$} & \multicolumn{3}{|c|}{ Tratamentos* } \\
\hline & T1 & T2 & T3 \\
\hline Umidade & $6,74 \pm 0,07^{a}$ & $4,25 \pm 0,05^{b}$ & $3,47 \pm 0,13^{c}$ \\
\hline Proteína & $8,60 \pm 0,18^{b}$ & $8,71 \pm 0,20^{b}$ & $9,09 \pm 0,01^{a}$ \\
\hline Matéria mineral & $1,48 \pm 0,02^{b}$ & $1,54 \pm 0,02^{\mathrm{a}}$ & $1,53 \pm 0,02^{\mathrm{a}}$ \\
\hline Lipídios & $15,59 \pm 0,30^{b}$ & $17,57 \pm 0,53^{a}$ & $18,07 \pm 0,59^{a}$ \\
\hline Fibra alimentar total $^{* *}$ & $12,82 \pm 0,02^{\mathrm{c}}$ & $33,85 \pm 0,05^{b}$ & $54,88 \pm 0,09^{a}$ \\
\hline Carboidratos ${ }^{* * *}$ & $54,78 \pm 0,02^{a}$ & $34,08 \pm 0,05^{b}$ & $12,96 \pm 0,09^{c}$ \\
\hline 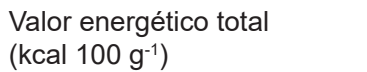 & $393,82 \pm 0,07^{\mathrm{a}}$ & $329,32 \pm 0,22^{b}$ & $250,82 \pm 0,37^{\circ}$ \\
\hline
\end{tabular}

Tratamento 1: 10\% FSG; Tratamento 2: 30\% FSG e Tratamento 3: 50\% FSG. *Médias com letras iguais na mesma linha indicam que as amostras não diferem entre si $(p<0,05)$ pelo teste de Tukey. Resultados expressos em base úmida. ${ }^{* *} \mathrm{Calcu}-$ lado a partir do conteúdo encontrado na farinha de trigo e na farinha de sementes de goiaba e a quantidade incorporada nas formulações. ${ }^{* * *}$ Calculados por diferença em relação aos demais componentes. 
Quando analisados estatisticamente, os resultados demonstraram que o tratamento 3 apresentou teor de proteína significativamente superior em relação aos tratamentos 1 e 2 , que não diferiram entre si. Para matéria mineral e lipídios, os teores do tratamento 1 foram significativamente inferiores aos biscoitos dos tratamentos com adição de 30 e 50\% de FSG. Considerando que os tratamentos 2 e 3 apresentam o maior grau de substituição da farinha de trigo pela FSG, os teores de lipídios e proteína relativamente elevados nos biscoitos destes tratamentos podem ser explicados pelo maior conteúdo desses componentes na FSG, como demonstrado anteriormente (Tabela 2).

Conforme observado na Tabela 3, todas as formulações do biscoito desenvolvidas diferiram significativamente entre si em relação aos teores de umidade, carboidrato, fibra alimentar total e valor energético. Os resultados obtidos, exceto para fibra alimentar, demonstraram um decréscimo gradual nos valores desses parâmetros à medida que aumentou o nível de substituição da farinha de trigo pela FSG. O contrário ocorreu com os teores de fibra alimentar total, que aumentaram com a adição de FSG nas formulações do biscoito. A maior proporção de fibra alimentar é atribuída ao elevado teor de fibra alimentar total encontrado na FSG (Tabela 2).

O biscoito do tratamento 1 , elaborado com $90 \%$ de farinha de trigo e apenas $10 \%$ de FSG apresentou-se com umidade maior que os biscoitos com concentrações mais elevadas de FSG na formulação. Segundo Bassinello et al., (2012), isso se deve ao fato de que no preparo da mistura, uma considerável quantidade de água é absorvida pelas proteínas da farinha de trigo (glutenina e gliadina) que interagem de maneira positiva para a formação da rede de glúten. Como a FSG não apresenta essas proteínas, consequentemente, não há formação da rede de glúten e, portanto, a água absorvida é facilmente evaporada. Esse fato pode explicar os menores teores de umidade verificados para os biscoitos dos tratamentos 2 e 3 , elaborados com as maiores concentrações de FSG em substituição parcial a farinha de trigo.

Comparando-se o teor de fibra alimentar total entre os tratamentos avaliados, o biscoito do tratamento 3 obteve $42 \mathrm{~g}$ a mais de fibra em sua composição que o biscoito do tratamento 1 . Todos os biscoitos formulados com diferentes concentrações de FSG podem ser considerados alimentos com alto conteúdo de fibra alimentar, pois segundo a legislação brasileira vigente (BRASIL, 2012), um alimento para ser considerado com alto conteúdo de fibra alimentar deve conter um teor mínimo

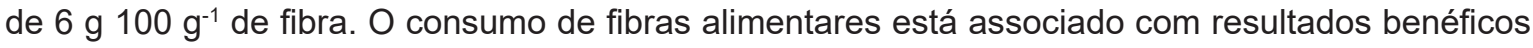
para o organismo humano e mesmo para a prevenção de algumas doenças crônicas (BELLO, 1995). Dessa forma, há grande interesse em elaborar produtos como pães e biscoitos com maior quantidade de fibras, já que estes são largamente consumidos pela população (GALDEANO; GROSSMANN, 2006).

Diversos estudos foram realizados com a finalidade de incorporar farinhas de coprodutos de frutas na elaboração de biscoitos. No trabalho de Aquino et al., (2010), o biscoito elaborado com

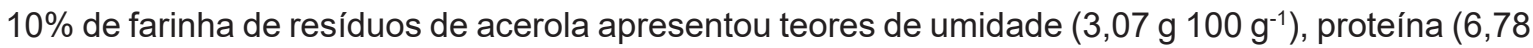

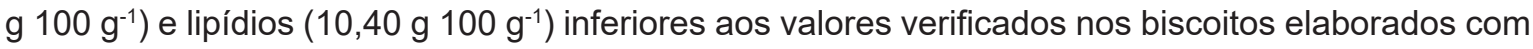
diferentes concentrações de FSG. No entanto, o conteúdo de cinzas no biscoito com resíduo de

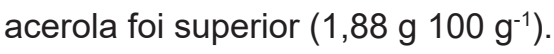

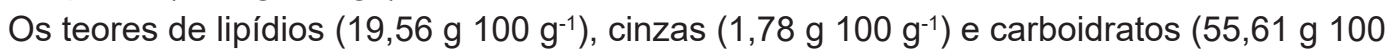
$\mathrm{g}^{-1}$ ) obtidos para os biscoitos tipo cookie elaborados com a semente de abóbora da fração peneirada (MOURA et al., 2010) foram maiores que os valores encontrados para os biscoitos desenvolvidos

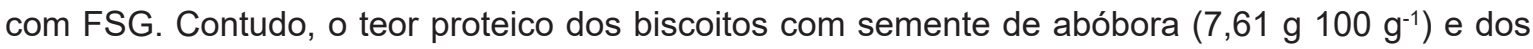
biscoitos elaborados com $10 \%$ de farinha de resíduos de acerola $\left(6,78 \mathrm{~g}_{100 \mathrm{~g}^{-1}}\right.$ ) (AQUINO et al., 2010), foram inferiores aos tratamentos dos biscoitos no presente estudo. Os teores lipídicos dos biscoitos com FSG foram inferiores aos valores verificados para os biscoitos formulados com semente de abóbora, porém esta característica confere vantagens a FSG em relação à semente de abóbora, como matéria-prima para a elaboração de alimentos com menor teor de lipídios e maior conteúdo de proteínas.

Nos biscoitos elaborados com diferentes concentrações de FSG, os valores energéticos 
variaram de 250,82 a $393,82 \mathrm{kcal} 100 \mathrm{~g}^{-1}$. Estes valores foram inferiores ao encontrado por Moura et al., (2010) para os biscoitos elaborados com semente de abóbora da fração peneirada $(430,92$ kcal $100 \mathrm{~g}^{-1}$ ), pelo fato destes conterem maior teor de lipídios na sua composição. Observa-se na Tabela 3, que o valor energético dos biscoitos foi reduzido com a adição de FSG. A redução energética dos biscoitos elaborados com $50 \%$ de FSG em relação aos tratamentos com 10 e $30 \%$ de FSG foi de 36,31 e 23,84\%, respectivamente, decorrente do menor conteúdo de carboidratos e do incremento de fibras nas formulações. Roberto (2012) avaliando barra de cereal com resíduos da industrialização da goiaba, também verificou um decréscimo de 11,2 a $20,4 \%$ do valor energético à medida que foram incorporados os resíduos da goiaba nas formulações.

\subsubsection{Avaliação física}

Os resultados médios das avaliações físicas nos diferentes tratamentos produzidos com substituição parcial da farinha de trigo por FSG estão apresentados na Tabela 4.

\section{TABELA 4 - RESPOSTAS DA CARACTERIZAÇÃO FÍSICA DOS BISCOITOS ELABORADOS COM DIFERENTES CONCENTRAÇÕES DE FSG.}

\begin{tabular}{|c|c|c|c|}
\hline \multirow{2}{*}{ Parâmetros físicos } & \multicolumn{3}{|c|}{ Tratamentos* } \\
\hline & $\mathrm{T} 1$ & T2 & T3 \\
\hline Peso pré-cocção (g) & $5,03 \pm 0,02^{a}$ & $5,03 \pm 0,03^{a}$ & $5,03 \pm 0,02^{\mathrm{a}}$ \\
\hline Peso pós-cocção (g) & $3,98 \pm 0,03^{c}$ & $4,09 \pm 0,03^{b}$ & $4,21 \pm 0,04^{a}$ \\
\hline Diferença $(\mathrm{g})$ & $-1,06 \pm 0,04^{a}$ & $-0,94 \pm 0,04^{b}$ & $-0,82 \pm 0,05^{c}$ \\
\hline Diâmetro pré-cocção (mm) & $26,65 \pm 0,96^{b}$ & $27,27 \pm 0,98^{a}$ & $26,56 \pm 0,77^{b}$ \\
\hline Diâmetro pós-cocção (mm) & $30,76 \pm 0,77^{c}$ & $31,24 \pm 0,56^{b}$ & $31,68 \pm 0,32^{a}$ \\
\hline Diferença $(\mathrm{mm})$ & $4,11 \pm 1,21^{b}$ & $3,97 \pm 1,06^{b}$ & $5,12 \pm 0,82^{\mathrm{a}}$ \\
\hline Espessura pré-cocção (mm) & $8,51 \pm 0,81^{c}$ & $9,06 \pm 0,72^{\mathrm{b}}$ & $9,71 \pm 0,80^{a}$ \\
\hline Espessura pós-cocção (mm) & $12,54 \pm 0,36^{a}$ & $11,91 \pm 0,18^{b}$ & $11,93 \pm 0,45^{b}$ \\
\hline Diferença (mm) & $4,03 \pm 0,84^{a}$ & $2,84 \pm 0,74^{b}$ & $2,2 \pm 0,90^{c}$ \\
\hline Fator de Expansão & $2,45 \pm 0,09^{b}$ & $2,63 \pm 0,06^{a}$ & $2,66 \pm 0,11^{a}$ \\
\hline
\end{tabular}

Tratamento 1: 10\% FSG; Tratamento 2: 30\% FSG e Tratamento 3: 50\% FSG. *Médias seguidas de letras iguais na mesma linha indicam não haver diferença significativa entre os resultados, pelo teste de Tukey $(p<0,05)$.

Os diferentes valores de diâmetroe espessura pré-cocção demonstramuma heterogeneidade entre os biscoitos produzidos, provavelmente em razão do método de elaboração utilizado, pois os biscoitos não foram moldados com auxílio de formas, mas modelados manualmente em função das características da massa. Desta forma, quaisquer diferenças obtidas nestas variáveis após a cocção podem estar relacionadas com esta particularidade, ou então com as interferências causadas pela presença da FSG na massa.

A variação de peso antes e após o forneamento dos biscoitos fornece a perda de peso no assamento (MORAES et al., 2010). O peso médio dos biscoitos após a cocção diferiu significativamente entre os tratamentos, o tratamento 3 apresentou a menor variação de peso enquanto que o tratamento 1, com a menor concentração de FSG na formulação apresentou a maior perda de peso dentre os tratamentos. A perda de peso verificada para os biscoitos dos tratamentos 1 e 3 , antes e após cocção foi 21 e $16 \%$, respectivamente. 
A menor variação de peso após a cocção dos biscoitos com maiores concentrações de FSG pode estar relacionada com o peso da farinha de sementes de goiaba, uma vez que esta matéria-prima em função da sua origem é mais pesada que a farinha de trigo convencional. Desta forma, a FSG e sua adição aos biscoitos podem ter alterado o rendimento em peso dos biscoitos após o forneamento.

Conforme pode ser verificado na Tabela 4, houve aumento no diâmetro após o forneamento em todos os tratamentos. A amostra do biscoito que apresentou o maior diâmetro $(31,68 \mathrm{~mm})$ depois de assado e também a maior diferença $(5,12 \mathrm{~mm})$ de diâmetro pré e pós-cocção foi o biscoito do tratamento 3, com a maior concentração de FSG na formulação. À medida que a concentração de FSG nos biscoitos diminuiu o diâmetro pós-cocção também se reduziu. Resultados semelhantes foram obtidos por Fasolin et al., (2007) em biscoitos tipo cookie elaborados com diferentes concentrações $(10,20$ e $30 \%)$ de farinha de banana verde. Os autores verificaram que o biscoito elaborado com $30 \%$ desta farinha também apresentou o maior diâmetro depois do forneamento e a maior diferença de diâmetro antes e após a cocção. Segundo esses autores, a adição de grandes quantidades de farinha de banana pode ter interferido na formação da rede de glúten do biscoito, fazendo com que a massa sofresse maior espalhamento durante a cocção, aumentando o diâmetro do biscoito.

A espessura média dos biscoitos antes da cocção apresentou diferença significativa entre os tratamentos, porém após o forneamento, apenas a formulação com 10\% de FSG apresentou o maior valor médio de espessura, diferindo significativamente das outras formulações. Assim, foi possível verificar que a espessura dos biscoitos tende a diminuir enquanto o diâmetro tende a aumentar, conforme aumenta a concentração de FSG nos tratamentos.

No trabalho de Silva, Silva e Chang (1998), os autores obtiveram um maior diâmetro e uma menor espessura para sua formulação controle, que correspondia ao biscoito padrão, quando esta foi comparada com as demais formulações compostas pela mistura de farinha de trigo e de jatobá (Hymenaea stigonocarpa Mart.) na proporção de 9:1. De acordo com os autores, essa diferença pode ter ocorrido devido à maior higroscopicidade dos materiais fibrosos presentes na farinha de jatobá, que retêm a água, dando maior consistência à massa evitando seu espalhamento, o que geralmente é a causa do maior diâmetro e menor espessura.

O fator de expansão foi maior para os biscoitos dos tratamentos 2 e 3 elaborados com as maiores concentrações de FSG, sem diferença significativa entre estes tratamentos. Os biscoitos do tratamento 1, com a menor concentração de FSG apresentaram maior espessura após a cocção e menor fator de expansão, diferindo significativamente dos demais tratamentos. Corroborando com os resultados obtidos no presente trabalho, Silva et al., (2001) relataram uma tendência de aumento na expansão e largura das formulações dos biscoitos com o aumento da concentração das farinhas de jatobá. Neste caso, os biscoitos elaborados com $25 \%$ de substituição da farinha de trigo pelas farinhas de jatobá-do-cerrado e de jatobá-da-mata obtiveram os maiores valores para o fator de expansão.

O índice de expansão de biscoitos tem sido utilizado como indicador de qualidade dos produtos. Segundo Perez e Germani (2007), o fenômeno de expansão de biscoitos é primariamente físico e está relacionado com a capacidade dos ingredientes em absorver água, como a farinha. Assim o acréscimo de componentes que possuem maior capacidade para reter água do que a farinha de trigo resulta em uma competição pela água livre presente na massa do biscoito limitando a taxa de expansão. Geralmente biscoitos elaborados com alto teor de fibras apresentam diminuição do fator de expansão (ASSIS et al., 2009; PEREZ; GERMANI, 2007; SILVA et al., 2001) o que não ocorreu no presente trabalho.

Assim como no trabalho de Fasolin et al., (2007) e ao contrário do observado por Silva, Silva e Chang (1998), a ausência de glúten na FSG e sua interferência na formação da rede de glúten da farinha de trigo, e ainda a provável menor higroscopicidade da FSG poderiam justificar o comportamento dos parâmetros físicos de diâmetro, espessura e fator de expansão obtidos no presente trabalho. Como observado na composição química, à FSG possui grande quantidade de 
fibra insolúvel, de forma a não interferir na absorção de água. Deste modo, em virtude das suas características, a presença da fibra pode ter ocasionado uma maior disponibilidade de água na massa, possibilitando a gelatinização do amido presente na farinha de trigo, ocasionando o aumento da expansão dos biscoitos elaborados com a FSG (MOURA et al., 2010).

\subsubsection{Características texturométricas}

A Tabela 5 apresenta os resultados da análise instrumental da textura realizada para os parâmetros de dureza e fraturabilidade dos biscoitos elaborados com diferentes concentrações de FSG em substituição a farinha de trigo.

\section{TABELA 5 - AVALIAÇÃO INSTRUMENTAL DA TEXTURA DOS BISCOITOS ELABORADOS COM DIFERENTES CONCENTRAÇÕES DE FSG.}

\begin{tabular}{ccc}
\hline Tratamentos & Dureza* $^{*}(\mathbf{g})$ & Fraturabilidade* $^{*}(\mathbf{m m})$ \\
\hline T1 & $8328,47 \pm 772,86^{\mathrm{b}}$ & $45,71 \pm 0,51^{\mathrm{a}}$ \\
T2 & $8653,83 \pm 342,31^{\mathrm{b}}$ & $44,86 \pm 0,22^{\mathrm{b}}$ \\
T3 & $11522,03 \pm 841,59^{\mathrm{a}}$ & $44,78 \pm 0,49^{\mathrm{b}}$ \\
\hline
\end{tabular}

Tratamento 1: 10\% FSG; Tratamento 2: 30\% FSG e Tratamento 3: 50\% FSG. *Médias seguidas por letras diferentes, na mesma coluna, diferem significativamente entre si pelo teste de Tukey $(p<0,05)$.

A textura é um elemento importante na qualidade do biscoito, e a dureza é um dos fatores que determina a aceitabilidade do alimento pelo consumidor e, assim como a fraturabilidade, é desejável que seus valores sejam baixos (ASSIS et al., 2009).

Com base nos dados expressos na Tabela 5 pode-se verificar que houve aumento da dureza no biscoito com $50 \%$ de FSG e redução da fraturabilidade dos biscoitos com 30 e $50 \%$ de FSG na formulação. No estudo instrumental da textura, a dureza foi significativamente maior para o biscoito do tratamento 3 e menos acentuada para os tratamentos 1 e 2 . Quanto à fraturabilidade, houve diferença significativa para o biscoito do tratamento 1 , que apresentou o maior valor de fraturabilidade em comparação com os demais tratamentos avaliados.

A dureza dos biscoitos, avaliada por método instrumental (texturômetro) é proporcional à força aplicada para ocasionar uma deformação, então, quanto maior a força requerida para penetrar o alimento, maior será sua dureza. A força máxima avaliada é dependente da formulação (qualidade da farinha, quantidade de açúcares e gorduras), umidade da massa e conservação (ASSIS et al., 2009). Neste sentido, o aumento da dureza nos diferentes tratamentos do biscoito pode ser interpretado como sendo o resultado da combinação do alto teor de FSG com predomínio de fibras insolúveis e teores reduzidos de fibra solúvel e água. Já a formulação, as condições de assamento e de resfriamento podem afetar ou controlar a quebra ou a fraturabilidade dos biscoitos (BASSINELLO et al., 2012)

Nos biscoitos com 30 e 50\% de FSG foi necessário diminuir a quantidade de água nas formulações (Tabela 1), devido à menor absorção de água pela farinha mista de trigo e sementes de goiaba para formar a massa. Avaliando as propriedades funcionais e tecnológicas da casca e da semente de goiaba, Roberto (2012) verificou que a casca da goiaba possui maior capacidade de hidratação que a semente do fruto, sendo que o valor encontrado para a semente foi de $1,60 \mathrm{~g}$ de água/g amostra. A capacidade de hidratação ou retenção mede a quantidade máxima de água absorvida que é retida pela amostra, e essa propriedade está diretamente relacionada com o teor de fibras solúveis presentes na amostra (SOUZA; FERREIRA; VIEIRA, 2008). Conforme Maier et al., (1993 apud MONTENEGRO et al., 2008), as fibras solúveis tendem a formar géis em contato com a água e desta forma auxiliam no aumento de retenção de umidade, promovendo a maciez em produtos de panificação. 


\subsubsection{Cor}

A cor dos biscoitos é uma das primeiras características observadas pelo consumidor afetando a aceitabilidade do produto (ZOULIAS; PIKNIS; OREOPOULOU, 2000). A coloração dos biscoitos está relacionada principalmente com os ingredientes da formulação, e segundo Perez e Germani (2007), biscoitos com maior teor de fibras costumam apresentar coloração mais escura.

Os resultados obtidos na avaliação de cor dos biscoitos são apresentados na Tabela 6. Todos os tratamentos apresentaram diferença significativa entre si, em todos os parâmetros de $\operatorname{cor}\left(L^{*}, a^{*}, b^{*}, C^{*} e h^{\circ}\right)$ avaliados. TABELA 6 - PARÂMETROS INSTRUMENTAIS DE COR $\left(L^{*}, A^{*}, B^{*}, C^{*} E H^{\circ}\right)$ DOS
BISCOITOS ELABORADOS COM DIFERENTES CONCENTRAÇÕES DE FSG.

\begin{tabular}{|c|c|c|c|}
\hline \multirow{2}{*}{ Parâmetros de Cor } & \multicolumn{3}{|c|}{ Tratamentos** } \\
\hline & T1 & T2 & T3 \\
\hline$L^{*}$ & $78,20 \pm 0,69^{a}$ & $65,48 \pm 0,73^{b}$ & $52,42 \pm 0,26^{c}$ \\
\hline$a^{*}$ & $+5,05 \pm 0,11^{c}$ & $+7,97 \pm 0,69^{b}$ & $+11,83 \pm 0,19^{a}$ \\
\hline$b^{*}$ & $+26,55 \pm 0,34^{c}$ & $+30,81 \pm 0,47^{b}$ & $+32,08 \pm 0,40^{a}$ \\
\hline$C^{*}$ & $27,02 \pm 0,36^{c}$ & $31,82 \pm 0,57^{b}$ & $34,19 \pm 0,44^{a}$ \\
\hline $\mathrm{h}^{\circ}$ & $79,32 \pm 0,12^{\mathrm{a}}$ & $75,18 \pm 0,29^{b}$ & $69,85 \pm 0,10^{c}$ \\
\hline
\end{tabular}
iguais não diferem significativamente entre si pelo teste de Tukey $(p<0,05)$.

A luminosidade $\left(\mathrm{L}^{*}\right)$ diminuiu com o aumento da substituição da farinha de trigo pela FSG, indicando que a cor dos biscoitos ficou mais escura. Os biscoitos do tratamento 3 apresentaram o menor valor de $L^{*}$ indicando o escurecimento do produto, enquanto o biscoito do tratamento 1 , com $10 \%$ de FSG apresentou maior luminosidade. Valores de luminosidade mais altos indicam maior reflectância da luz, traduzindo-se em produtos com coloração clara.

Em relação à coloração dos biscoitos, a substituição da farinha de trigo pela FSG possibilitou um incremento nas colorações amarelo e vermelha dos tratamentos. Observa-se na Tabela 6 um aumento nos valores do parâmetro $a^{*}$ conforme a FSG foi adicionada nos biscoitos, ou seja, a intensidade de coloração vermelha foi aumentando proporcionalmente a adição de FSG. Desta forma, os biscoitos do tratamento 3 apresentou o maior desvio para o vermelho $\left(+a^{*}\right)$ indicando coloração mais escura na crosta. Piovesana, Bueno e Klajn (2013) também observaram coloração mais intensa em biscoitos formulados com percentuais mais elevados de farinha de bagaço de uva, em função da concentração expressiva de pigmentos antociânicos presentes nesta farinha.

Assim como a coordenada de cor $a^{*}$, os valores de $b^{*}$ que variam de azul (-b*) a amarelo $\left(+b^{*}\right)$, também apresentaram uma tendência de aumento proporcional à presença de FSG nos tratamentos do biscoito. Assim, o biscoito com $50 \%$ de FSG apresentou os maiores valores de $+b^{*}$ com diferença significativa entre os demais tratamentos.

Os biscoitos do tratamento 3, com a maior concentração de FSG na formulação apresentou maior intensidade de cor $\left(C^{*}\right)$ se comparado aos tratamentos 1 e 2 . Para o ângulo de tonalidade $\left(h^{\circ}\right)$, os valores obtidos foram significativamente diferentes entre os tratamentos, indicando que 0 aumento de FSG nas formulações teve influência sobre o ângulo de tonalidade das amostras.

\subsubsection{Avaliação sensorial}

As análises sensoriais desenvolvidas no presente estudo foram conduzidas com o intuito de verificar a aceitação e a preferência dos provadores frente às características gerais dos biscoitos formulados a partir da substituição parcial da farinha de trigo por 10, 30 e 50\% de FSG. 
O painel de provadores no teste de ordenação quanto à preferência e no teste afetivo de aceitação contou com a presença de 70 e 61 participantes não treinados na primeira e na segunda sessão, respectivamente. Nas duas sessões das análises sensoriais predominaram provadores do gênero feminino ( 79 e $77 \%$ ), e em ambas as análises, os provadores em sua maioria apresentaramse na faixa etária compreendida entre 18 e 25 anos (66 e 69\%), seguida da faixa etária de 26 a 35 anos (19 e $21 \%)$.

Os resultados obtidos na avaliação sensorial pelo teste de ordenação de preferência são apresentados na Tabela 7.

\section{TABELA 7 - MÓDULO DAS DIFERENÇAS ENTRE OS PARES DE SOMATÓRIO TOTAL DO TESTE DE ORDENAÇÃO DE PREFERÊNCIA PARA OS ATRIBUTOS DE COR, AROMA, SABOR E TEXTURA NOS DIFERENTES TRATAMENTOS DOS BISCOITOS.}

\begin{tabular}{|c|c|c|c|}
\hline \multirow{2}{*}{ Amostra } & Tratamento 1 & Tratamento 2 & Tratamento 3 \\
\hline & \multicolumn{3}{|c|}{ Cor } \\
\hline Somatório Totala & $138^{b}$ & $170^{\mathrm{a}}$ & $112^{\mathrm{b}}$ \\
\hline Diferença x I & & $32^{*}$ & 26 \\
\hline \multirow[t]{2}{*}{ Diferença $\mathrm{x}$ II } & & & $58^{*}$ \\
\hline & \multicolumn{3}{|c|}{ Aroma } \\
\hline Somatório Totala & $108^{b}$ & $161^{a}$ & $151^{a}$ \\
\hline Diferença x I & & $53^{*}$ & $43^{*}$ \\
\hline \multirow[t]{2}{*}{ Diferença $x$ II } & & & 10 \\
\hline & \multicolumn{3}{|c|}{ Sabor } \\
\hline Somatório Totala & $109^{b}$ & $152^{\mathrm{a}}$ & $159^{a}$ \\
\hline Diferença x I & & $43^{*}$ & $50^{*}$ \\
\hline \multirow[t]{2}{*}{ Diferença $\mathrm{x}$ II } & & & 7 \\
\hline & \multicolumn{3}{|c|}{ Textura } \\
\hline Somatório Totala & $157^{a}$ & $143^{\mathrm{ab}}$ & $120^{b}$ \\
\hline Diferença x I & & 14 & $37^{*}$ \\
\hline Diferença x II & & & 23 \\
\hline \multicolumn{4}{|l|}{ Tratamentos: 3} \\
\hline \multicolumn{4}{|l|}{ Provadores: 70} \\
\hline Valor crítico tabelado: 28 & & & \\
\hline
\end{tabular}

Tratamento 1: 10\% FSG; Tratamento 2: 30\% FSG e Tratamento 3: 50\% FSG. *Significativo ao nível de 5\% se a diferença entre as somas das ordens de duas amostras diferirem por um valor maior ou igual ao valor crítico tabelado (Tabela de Newel-McFarlane, 1987). amaior somatório corresponde a maior preferência

Para o atributo de cor, os resultados do teste de ordenação de preferência demonstraram uma maior aprovação pelo biscoito do tratamento 2. O somatório obtido por esta amostra foi significativamente superior ao alcançado pelos tratamentos 1 e 3 .

Para aroma e sabor, não houve diferença significativa ao nível de $5 \%$ entre os somatórios obtidos para os biscoitos dos tratamentos 2 e 3, porém, de acordo com a Tabela 7, essas amostras diferiram significativamente do somatório obtido para o biscoito do tratamento 1 . Com relação à textura dos biscoitos, o somatório obtido para o tratamento com adição de $30 \%$ de FSG não foi significativamente diferente dos demais tratamentos testados e avaliados. No entanto, comparandose os tratamentos 1 e 3 , os provadores indicaram como preferência a textura do biscoito elaborado com $10 \%$ de FSG, visto que, esta amostra apresentou somatório significativamente maior que a 
amostra do biscoito com $50 \%$ de FSG.

Na Tabela 8 são apresentados os escores médios obtidos para os atributos sensoriais avaliados no teste de aceitação.

\section{TABELA 8 - ESCORES MÉDIOS DOS ATRIBUTOS SENSORIAIS AVALIADOS NO TESTE DE ACEITAÇÃO DOS BISCOITOS ELABORADOS COM DIFERENTES CONCENTRAÇÕES DE FSG.}

\begin{tabular}{|c|c|c|c|}
\hline \multirow{2}{*}{ Atributos Sensoriais } & \multicolumn{3}{|c|}{ Tratamentos* } \\
\hline & T1 & T2 & T3 \\
\hline Cor & $5,21 \pm 1,05^{\mathrm{ab}}$ & $5,64 \pm 0,91^{\mathrm{a}}$ & $5,11 \pm 1,44^{b}$ \\
\hline Aroma & $4,80 \pm 0,98^{b}$ & $5,59 \pm 0,90^{a}$ & $5,59 \pm 1,12^{a}$ \\
\hline Sabor & $4,95 \pm 1,15^{b}$ & $6,05 \pm 0,83^{a}$ & $5,82 \pm 1,04^{a}$ \\
\hline Textura & $5,30 \pm 1,10^{a}$ & $5,15 \pm 1,05^{a}$ & $4,62 \pm 1,28^{b}$ \\
\hline Aceitação Global & $5,03 \pm 1,11^{b}$ & $5,56 \pm 0,83^{a}$ & $5,36 \pm 1,14^{a b}$ \\
\hline
\end{tabular}

Tratamento 1: 10\% FSG; Tratamento 2: 30\% FSG e Tratamento 3: 50\% FSG. Escores: 7 - gostei muitíssimo; 6 - gostei muito; 5 - gostei; 4 - indiferente; 3 - desgostei; 2 - desgostei muito; 1 - desgostei muitíssimo. *Médias na mesma linha com letras iguais não diferem significativamente entre si pelo teste de Tukey $(p<0,05)$.

Quando comparados os valores instrumentais da cor ( $\left.\mathrm{L}^{*}, \mathrm{a}^{*}, \mathrm{~b}^{*}\right)$ (Tabela 6) com os resultados da análise sensorial para o atributo cor (Tabela 8) observa-se uma relação entre estes valores, para os tratamentos 2 e 3 , uma vez que houve diferença significativa entre estes tratamentos, para ambas as análises, sendo assim perceptíveis para os avaliadores.

Os escores médios de aceitação para o atributo de cor obtidos no teste afetivo demonstraram que o biscoito do tratamento 1 não foi estatisticamente diferente dos tratamentos 2 e 3 , apesar de os tratamentos testados possuírem diferentes concentrações de FSG. O biscoito formulado com $30 \%$ de FSG obteve estatisticamente a maior média de aceitação para este atributo, em relação ao tratamento 2. Este resultado reforça o encontrado no teste de ordenação da preferência, que demonstrou uma maior aprovação pela amostra do tratamento 2 em relação à cor.

Para os atributos de aroma e sabor, os escores médios verificados situaram-se entre 4 e 6 correspondendo aos termos "indiferente" e "gostei muito" na escala hedônica. Para estes dois atributos, o biscoito do tratamento 1 foi o menos apreciado entre os avaliadores, diferindo significativamente dos demais tratamentos. Provavelmente por ter sido elaborada com o menor percentual de FSG, esta formulação não foi capaz de conferir aroma e sabor semelhante ao de goiaba como foi verificado nas formulações com 30 e $50 \%$ de FSG.

Quanto ao atributo textura observou-se que, o tratamento 3 com o maior percentual de FSG na formulação obteve o menor escore médio de aceitação em relação a este atributo, diferindo estatisticamente dos demais tratamentos. Este fato está relacionado com a dureza instrumental das amostras (Tabela 10), onde a formulação com 50\% de FSG apresentou a maior dureza e as formulações com 10 e $30 \%$ a menor dureza. Pode-se verificar com isso que entre a textura da análise sensorial e a dureza instrumental a relação é inversamente proporcional às médias obtidas. Além disso, a baixa pontuação para a textura no tratamento 3 pode estar relacionada com a característica arenosa do biscoito, percebida sensorialmente pelos provadores. Provavelmente este fato tenha ocorrido devido à presença de grânulos em razão da alta concentração de FSG presente nesta formulação. 
Com relação à aceitação global dos biscoitos elaborados com diferentes concentrações de FSG, todas as amostras tiveram boa aceitação global pelos provadores, com escores de aceitação correspondendo ao termo hedônico "gostei" (Tabela 8). Os tratamentos 1 e 2 diferenciaram-se estatisticamente entre si, mas não diferiram em relação ao biscoito do tratamento 3 , em termos de aceitação.

No estudo de Aquino et al., (2010) os autores observaram que as notas atribuídas para os parâmetros de aparência, aroma, sabor e impressão global foram significativamente menores com o aumento da concentração da farinha de resíduos de acerola. Segundo os autores, o cookie formulado com $20 \%$ desta farinha foi o menos apreciado entre os provadores, principalmente pela variação na cor do biscoito e pela presença de grânulos verificada pelos provadores. ,

Quanto ao índice de aceitabilidade dos biscoitos elaborados com FSG (Figura 1), verificouse que para os parâmetros sensoriais investigados os valores foram superiores a $70 \%$, com exceção dos atributos de aroma para o tratamento $1(68,62 \%)$ e textura para o tratamento $3(66,04 \%)$.

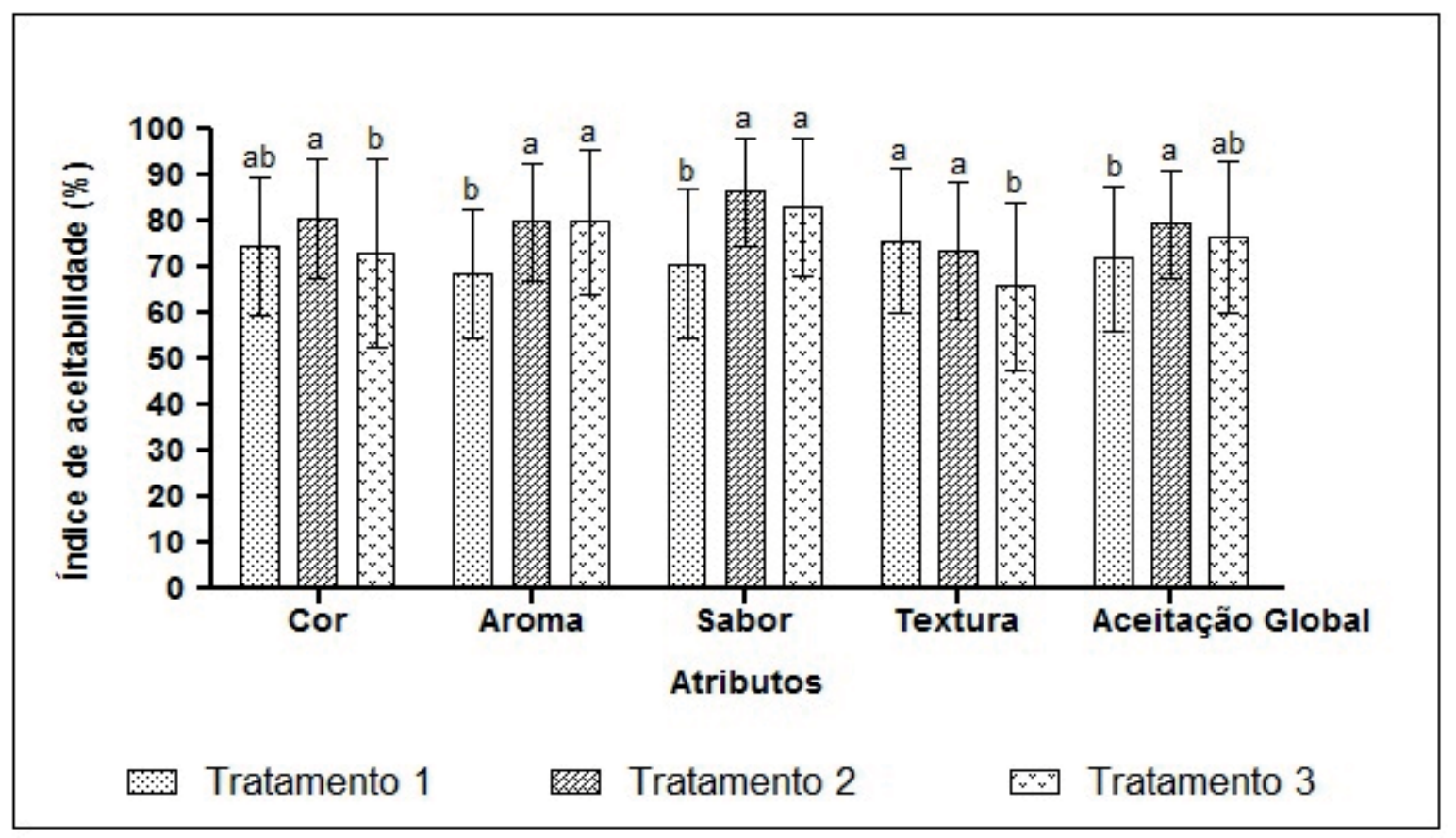
FIGURA 1 - ÍNDICE DE ACEITABILIDADE (\%) DOS ATRIBUTOS SENSORIAIS AVALIADOS NOS BISCOITOS ELABORADOS COM DIFERENTES CONCENTRAÇÕES DE FSG. TRATAMENTO 1: $10 \%$ FSG; TRATAMENTO 2: $30 \%$ FSG E TRATAMENTO 3: $50 \%$ FSG. *BARRAS COM LETRAS IGUAIS NÃO DIFEREM SIGNIFICATIVAMENTE ENTRE SI PELO TESTE DE TUKEY $(P<0,05)$.

Os biscoitos com 30 e 50\% de FSG na formulação apresentaram os maiores índices de aceitabilidade para os atributos de aroma $(79,86 \%)$ e sabor $(86,42 \%$ e $83,14 \%$, respectivamente), sem diferença significativa entre os tratamentos. Este resultado supera a expectativa proposta por Moura et al., (2010), de que em geral, biscoitos com adição de farinhas de cascas e sementes de vegetais em níveis de até $25 \%$, com intuito de aumentar o teor de fibras, ainda resultam em bom índice de aceitação.

Em geral, os resultados obtidos para a aceitabilidade demonstraram que as concentrações de FSG aplicadas nas formulações, não interferiram negativamente na qualidade sensorial dos biscoitos. Desta forma, os biscoitos formulados com FSG podem ser viáveis comercialmente, pois apresentaram índice de aceitabilidade acima de 70\%, considerados, portanto, satisfatórios. 
Na Figura 2 está demonstrada a intenção de compra dos produtos avaliados. Os maiores percentuais de respostas para a estimativa da intenção de compra dos biscoitos ocorreram para a atitude "provavelmente eu compraria", à exceção do tratamento 1, que obteve maior percentual de respostas "talvez eu compraria/talvez eu não compraria". O maior número de ocorrências para a atitude "provavelmente eu compraria" foi verificada para o tratamento $2(51 \%)$, embora 33 e $31 \%$ dos provadores responderam que certamente comprariam os biscoitos dos tratamentos $2 \mathrm{e}$ 3 , respectivamente. Apenas $2 \%$ dos provadores indicaram certeza em não comprar o biscoito do tratamento 3 , em decorrência da textura que apresentava o produto.

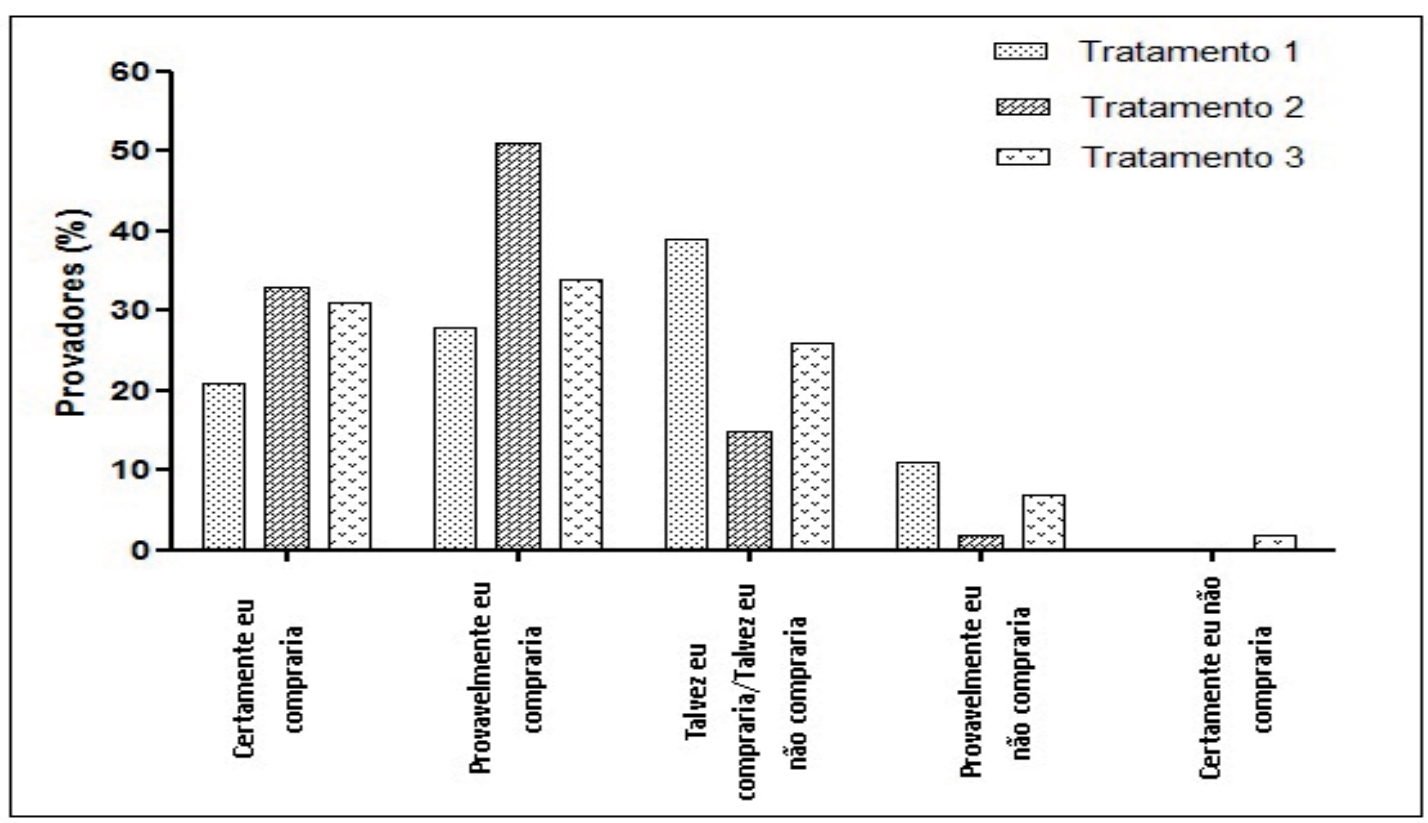

\section{FIGURA 2 - INTENÇÃO DE COMPRA DOS BISCOITOS ELABORADOS COM DIFERENTES CONCENTRAÇÕES DE FSG. TRATAMENTO 1: 10\% FSG; TRATAMENTO 2: $30 \%$ FSG E TRATAMENTO 3: 50\% FSG.}

No trabalho de Piovesana, Bueno e Klajn (2013), os biscoitos enriquecidos com diferentes proporções de aveia e farinha de bagaço de uva apresentaram aceitável intenção de compra pelos julgadores. Segundo os autores, as notas obtidas para o teste de intenção de compra destes produtos foram representadas pelas escalas "talvez comprasse/talvez não comprasse" e "possivelmente compraria".

Mesmo que as respostas obtidas em laboratório pelos potenciais compradores do biscoito com adição de FSG não reflitam exatamente suas atitudes reais de compra, os resultados obtidos fornecem uma estimativa de sua intenção em comprar este produto.

\section{CONCLUSÃO}

Em razão do rendimento de FSG obtido, pode-se inferir que a semente de goiaba é viável para o processo de obtenção dessa farinha, visando o enriquecimento dos alimentos ou a substituição parcial da farinha de trigo podendo ser utilizada em produtos de panificação, como biscoitos.

A FSG apresentou baixa atividade de água e teor de umidade em acordo com o padrão exigido pela legislação e demonstrou ser uma importante fonte de proteínas, lipídios e fibras, principalmente fibra alimentar insolúvel. $O$ incremento dessa farinha aos biscoitos formulados influenciou na composição química, nos atributos de cor $\left(L^{*}, a^{*}\right.$ e $\left.b^{*}\right)$, no peso e diâmetro pós- 
cocção e na textura instrumental. Os biscoitos elaborados apresentaram propriedades sensoriais aceitáveis, sendo os percentuais de substituição utilizados neste estudo aceitos pelos julgadores, dentre todos os atributos avaliados.

Os resultados obtidos demonstram o potencial de aproveitamento da semente de goiaba como farinha, constituindo uma nova proposta para a utilização destas sementes e o desenvolvimento de alternativas alimentícias.

\title{
ALTERNATIVE TECHNOLOGY FOR THE USE OF GUAVA SEEDS (PSIDIUM GUAJAVA L.) AS FLOUR FOR COOKIE PRODUCTION
}

\begin{abstract}
This study aimed to investigate the potential use of guava seeds as flour for cookies production. The physicochemical composition of guava seeds flour (GSF) was determined and then cookies were prepared with 10,30 and $50 \%$ of GSF partially substituting wheat flour. Cookies were evaluated regarding their physical, chemical and sensory characteristics. The GSF showed that the moisture content is in accordance with the standard required by Brazilian law, and that there are high levels of protein, lipids and dietary fiber, especially the insoluble fraction. The gradual addition of this flour to the cookies elevated the lipids and dietary fiber levels and reduced the moisture content, carbohydrate and energy value. The addition of GSF to the cookies influenced the parameters in relation to color, instrumental hardness, weight and diameter post-cooking. The cookies presented acceptable sensory properties. Furthermore, the percentage of substitution used in this study was accepted by the judges, among all attributes evaluated. In conclusion, the guava seed is an alternative ingredient to be used considering that it is a product which is usually discarded. Therefore, the flour obtained from this co-product is an alternative to partially substitute wheat flour in cookies, in order to improve its nutritional value without interfering with the sensory characteristics.
\end{abstract}

KEYWORDS: FLOUR MIX; COOKIE; CHARACTERIZATION; SENSORY ANALYSIS.

\section{REFERÊNCIAS}

1 AACC. American Association of Cereal Chemists. Approved methods of the American Association of Cereal Chemists. 9 ed. Saint Paul: AACC, 1995. 1 v. (paginação irregular).

2 AACC. American Association of Cereal Chemists. Approved methods of the American Association of Cereal Chemists. 10 ed. Saint Paul: AACC, 2000. 2 v. (paginação irregular).

3 ABNT. ASSOCIAÇÃO BRASILEIRA DE NORMAS TÉCNICAS. NBR 12806: Análise sensorial dos alimentos e bebidas. Rio de Janeiro, 1993. 8 p.

4 ABUD, A. K. S.; NARAIN, N. Incorporação da farinha de resíduo do processamento de polpa de fruta em biscoitos: uma alternativa de combate ao desperdício. Brazilian Journal of Food Technology, Campinas, v. 12, n. 4, p. 257-265. 2009.

5 AOAC, Association of Official Analytical Chemists. Official Methods of Analysis of AOAC International. 18 $8^{\text {th }}$ ed., Current through revision 2, 2007. Washington: AOAC, 1750p. 2005.

6 AQUINO, A. C. M. S. et al. Avaliação físico-química e aceitação sensorial de biscoitos tipo cookies elaborados com farinha de resíduos de acerola. Revista do Instituto Adolfo Lutz, São Paulo, v.69, n.3, p. 379-86. 2010.

7 ASSIS, L. M. et al. Propriedades nutricionais, tecnológicas e sensoriais de biscoitos com substituição de farinha de trigo por farinha de aveia ou farinha de arroz parboilizado. Alimentos e Nutrição, Araraquara, v. 20, n. 1, p. 15-24, 2009.

8 BASSINELLO, P. Z. et al. Potencial de aproveitamento de farinhas de quirera de arroz e bandinha de feijão em biscoitos tipo cookie. Santo Antônio de Goiás, GO: Embrapa Arroz e Feijão, 2012.8p. (Embrapa Arroz e Feijão. Comunicado Técnico, 204). 
9 BELLO, J. Los alimentos funcionales nutraceuticos: funciones saludables de algunos componentes de los alimentos. Alimentaria, n. 267, p. 49-58, 1995.

10 BLIGH, E.G.; DYER, W.J. A rapid method of total lipid extraction and purification. Canadian Journal of Biochemistry and Physiology, Ottawa, v.37, p.911-917. 1959.

11 BOEKEL, S.V. et al. Elaboração de farinha mista extrusada de arroz, soja e resíduo de laranja-pêra como fonte de fibra alimentar. Magistra, Cruz das Almas, v.23, n.4, p. 243-251, 2011.

12 BOURNE, M. C. Texture profile analysis. Food Technology, Chicago, v.7, n. 32, p. 62- 66. 1978.

13 BRASIL. Agência Nacional de Vigilância Sanitária. Resolução n. 263, de 22 de setembro de 2005. Regulamento técnico para produtos de cereais, amidos, farinhas e farelos. Diário Oficial [da] República Federativa do Brasil, Brasília, 23 de setembro de 2005.

14 BRASIL. Agência Nacional de Vigilância Sanitária. Resolução n. 360, de 23 de dezembro de 2003. Regulamento técnico sobre rotulagem nutricional de alimentos embalados. Diário Oficial [da] República Federativa do Brasil, Brasília, 26 de dezembro de 2003.

15 BRASIL. Agência Nacional de Vigilância Sanitária. Resolução n. 54, de 22 de novembro de 2012. Regulamento Técnico sobre Informação Nutricional Complementar. Diário Oficial [da] República Federativa do Brasil, Brasília, 12 de novembro de 2012.

16 BRASIL. Conselho Nacional de Saúde. Resolução n. 466, de 12 de dezembro de 2012. Aprova as diretrizes e normas regulamentadoras de pesquisas envolvendo seres Humanos. Diário Oficial [da] República Federativa do Brasil, Brasília, 13 de junho de 2013.

17 FASOLIN, L. H. et al. Biscoitos produzidos com farinha de banana: avaliações química, física e sensorial. Ciência e Tecnologia de Alimentos, Campinas, v. 27, n.3, p. 524-529. 2007.

18 FERREIRA, V. L. P. et al. Análise sensorial: testes discriminativos e afetivos. Campinas: SBCTA, 2000. 127p. (Manual - Série Qualidade).

19 FONTANARI, G. G. et al. Isolado protéico de semente de goiaba (Psidium guajava): caracterização de propriedades funcionais. Ciência e Tecnologia de Alimentos, Campinas, v. 27, p. 73-79. 2007.

20 GALDEANO, M. C.; GROSSMANN, M. V. E. Oat hulls treated with alkaline hydrogen peroxide associated with extrusion as fi ber source in cookies. Ciência e Tecnologia de Alimentos, Campinas, v. 26, n. 1, p. 123-126, 2006.

21 GUIMARÃES, R. R.; FREITAS, M. C. J.; SILVA, V. L. M. Bolos simples elaborados com farinha da entrecasca de melancia (Citrullus vulgaris, sobral): avaliação química, física e sensorial. Ciência e Tecnologia de Alimentos, Campinas, v. 30, n. 2, p. 354-363. 2010.

22 IAL. INSTITUTO ADOLFO LUTZ. Métodos físico-químicos para análise de alimentos. 1. ed. digital. São Paulo, 2008. $1020 \mathrm{p}$.

23 MATIAS, M. F. O. et al. Use of fibres obtained from the cashew (Anacardium ocidentale, L) and guava (Psidium guayava) fruits for enrichment of food products. Brazilian Archives of Biology and Technology, Curitiba, v. 48, n. spe. 2005

24 MONTENEGRO, F. M. et al. Biscoitos de polvilho azedo enriquecidos com fibras solúveis e insolúveis. Ciência e Tecnologia de Alimentos, Campinas, v. 28, n. Supl, p. 184-191. 2008.

25 MORAES, K. S. et al. Avaliação tecnológica de biscoitos tipo cookie com variações nos teores de lipídio e de açúcar. Ciência e Tecnologia de Alimentos, Campinas, v.30, n. Supl.1, p. 233-242. 2010.

26 MOURA, F.A. et al. Biscoitos tipo "cookie" elaborados com diferentes frações de semente de abóbora (Curcubita maxima). Alimentos e Nutrição, Araraquara, v. 21, n. 4, p. 579-585. 2010.

27 NASCIMENTO, R. J.; ARAÚJO, C. R.; MELO, E. A. Atividade antioxidante de extratos de resíduo agroindustrial de goiaba (Psidium guajava L.). Alimentos e Nutrição, Araraquara, v. 21, n. 2, p. 209-216. 2010.

28 NEWELL, G. J.; MACFARLANE, J. D. Expanded tables for multiple comparison procedures in the analysis of ranked data. Journal of Food Science, Chicago, p.1721-1725. 1987.

29 PEREZ, P. M. P.; GERMANI, R. Elaboração de biscoitos tipo salgado, com alto teor de fibra alimentar, utilizando farinha de berinjela (Solanum melongena, L.). Ciência e Tecnologia de Alimentos, Campinas, v. 27, n. 1, p.186-192. 2007.

30 PIOVESANA, A.; BUENO, M. M.; KLAJN, V. M. Elaboração e aceitabilidade de biscoitos enriquecidos com aveia e farinha de bagaço de uva. Brazilian Journal of Food Technology, Campinas, v. 16, n. 1, p. 68-72. 2013. 
31 ROBERTO, B.S. Resíduo de goiaba: metabolismo em ratos aplicabilidade em barras de cereais. 2012.150 p. Dissertação (Mestrado em Ciência e Tecnologia dos Alimentos) - Universidade Federal de Santa Maria, Santa Maria, 2012.

32 SANTANA, M . F. S.; SILVA, I, C. Elaboração de biscoitos com resíduo da extração de suco de caju. Belém, PA: Embrapa Amazônia Oriental, 2008. 4p. (Embrapa Amazônia Oriental. Comunicado Técnico, 214).

33 SANTOS, A. A. O. et al. Elaboração de biscoitos de chocolate com substituição parcial da farinha de trigo por polvilho azedo e farinha de albedo de laranja. Ciência Rural, Santa Maria, v.41, n.3, p.531-536. 2011.

34 SILVA, M. R. et al. Utilização tecnológica dos frutos de jatobá-do-cerrado e de jatobá-da-mata na elaboração de biscoitos fontes de fibra alimentar e isentos de açúcares. Ciência e Tecnologia de Alimentos, Campinas, v. 21, n. 2, p. $176-182$. 2001.

35 SILVA, M. R.; SILVA, M. P. A. P.; CHANG, Y. K. Utilização da farinha de Jatobá (Hymenaea stigonocarpa Mart.) na elaboração de biscoitos tipo cookie e avaliação de aceitação por testes sensoriais afetivos univariados e multivariados. Ciência e Tecnologia de Alimentos, Campinas, v. 18, n. 1, p. 25-34. 1998.

36 SOUZA, M. W., FERREIRA, T. B., VIEIRA, I. F. Composição centesimal e propriedades funcionais tecnológicas da farinha da casca do maracujá. Alimentos e Nutrição, Araraquara, v.19, n.1, p.33-36. 2008.

37 TACO, Tabela Brasileira de Composição de Alimentos - NEPA/UNICAMP. 4. ed. rev. e ampl., Campinas: NEPAUNICAMP, $2011.161 \mathrm{p}$.

38 UCHOA, A. M. A. et al. Parâmetros físico-químicos, teor de fibra bruta e alimentar de pós alimentícios obtidos de resíduos de frutas tropicais. Segurança Alimentar e Nutricional, Campinas, v. 15, n. 2, p. 58-65. 2008.

39 ZOULIAS, E. I.; PIKNIS, S.; OREOPOULOU, V. Effect of sugar replacement by polyols and acesulfame-K on properties of low-fat cookies. Journal of the Science of Food and Agriculture, v. 80, n. 14, p. 2049-2056. 2000.

\section{AGRADECIMENTOS}

Ao Setor de Processamento de Frutas e Hortaliças do Colégio Politécnico da Universidade Federal de Santa Maria, pelo fornecimento dos coprodutos da goiaba. À Coordenação de Aperfeiçoamento de Pessoal de Nível Superior (CAPES), ao suporte financeiro. 